\title{
Roger Bautier, Elisabeth Cazenave : Les origines d'une conception moderne de la communication, Gouverner l'opinion au XIXe siècle
}

Presses Universitaires de Grenoble, Collection La Communication en plus, 2000, $143 \mathrm{p}$.

\section{Patrice de la Broise}

\section{(2) OpenEdition Journals}

\section{Édition électronique}

URL : http://journals.openedition.org/edc/1142

DOI : $10.4000 /$ edc. 1142

ISSN : 2101-0366

\section{Éditeur}

Université de Lille

\section{Édition imprimée}

Date de publication : 1 mars 2001

Pagination : 151-152

ISBN : 2-9514961-1-7

ISSN : $1270-6841$

\section{Référence électronique}

Patrice de la Broise, «Roger Bautier, Elisabeth Cazenave : Les origines d'une conception moderne de la communication, Gouverner l'opinion au XIXe siècle », Études de communication [En ligne], 23 | 2001, mis en ligne le 10 janvier 2010, consulté le 22 septembre 2020. URL : http://journals.openedition.org/ edc/1142 ; DOI : https://doi.org/10.4000/edc. 1142 


\section{Roger Bautier, Elisabeth Cazenave : Les origines d'une conception moderne de la communication, Gouverner l'opinion au XIXe siècle}

Presses Universitaires de Grenoble, Collection La Communication en plus, 2000, $143 \mathrm{p}$.

Patrice de la Broise

\section{RÉFÉRENCE}

Les origines d'une conception moderne de la communication, Gouverner l'opinion au XIXe siècle, Presses Universitaires de Grenoble, Collection La Communication en plus, 2000,143 p.

1 Le recours à l'histoire est non seulement utile mais nécessaire à la compréhension du rôle des médias dans l'espace public. On sait, notamment par les travaux de J. Habermas, que le XVIIIe siècle marque l'émergence d'une opinion publique. À cette époque, pourtant, la liberté de la presse ne triomphe guère qu'en Europe du Nord, aux Pays-Bas et en Grande-Bretagne en particulier. La presse française, quant à elle, ne connaît son véritable essor qu'à la Restauration.

On comprend donc que Roger Bautier et Elisabeth Cazenave cherchent plus volontiers les origines d'une conception moderne de la communication au XIXe siècle. De celui-là, et de la Liberté de la presse, Honoré Daumier a laissé quelques caricatures célèbres. Mais les discours, les interventions parlementaires, les articles disent autrement l'ampleur des débats qui, entre 1814 et 1914, fondent la communication moderne. Il faut, au passage, saluer la performance des auteurs qui, dans un format relativement modeste, ont su extraire et confronter une très grande diversité d'archives. L'usage fréquent de la 
citation sert toujours utilement, et sans parti pris, la restitution des affrontements politiques et joutes intellectuelles de l'époque.

Ainsi, les positions (libérales, dogmatiques, doctrinaires, républicaines) diversement adoptées jusqu'à la fin du Second Empire à l'égard de la presse sont particulièrement édifiantes, tant sur la question de l'exercice du pouvoir (chapitre $1:$ reconstruire un ordre social) que sur les stratégies d'information et de pénétration des classes populaires (chapitre $2:$ mobiliser les classes populaires).

4 Les positions des libéraux, défenseurs de la presse en ce qu'elle " est nécessaire comme la parole aux citoyens de toutes les classes » et «force les hommes politiques à venir tour à tour comparaître devant le tribunal de l'opinion ", contrastent avec le dogmatisme saint-simonien et la réserve positiviste d'Auguste Comte à l'égard d'un " pouvoir spirituel » laissé aux mains des journalistes. Les Républicains ne sont pas en reste... saluant une "génération nouvelle de la démocratie ", ils n'en demeurent pas moins sceptiques devant le "flot de l'information à outrance » et le sensationnel d'une presse mal libérée. Et Zola, accusant le tapage du siècle, de conclure que " le citoyen, censé être informé pour se gouverner, perd en bonheur ce qu'il gagne en information ».

Dans un second chapitre Roger Bautier et Elisabeth Cazenave montrent combien la mobilisation des classes populaires, - toujours considérées comme devant être éduquées et/ ou amenées à prendre conscience d'elles mêmes, participe grandement des stratégies de gouvernement de l'opinion. C'est que la presse, en offrant potentiellement une tribune aux ouvriers, contribue aussi à les constituer en classe. Les socialistes, bien que peu enclins à servir l'opinion publique, entendent faire connaître l'esprit qui anime le monde ouvrier. La multiplication des titres (Le bon sens, L'Artisan, L'Atelier, ...) et le succès d'une presse bon marché auront tôt fait d'inquiéter mais aussi d'inspirer républicains et catholiques, eux-mêmes soucieux de conquérir un lectorat - et un électorat - qui leur échappe.

6 Le XIXe siècle s'achève à peine que, déjà, les principales questions relatives au rôle des médias et à leur influence, à la représentativité des journalistes, à l'usage de la parole et de l'écrit, à l'essor de la communication sont posées. Roger Bautier et Elisabeth Cazenave leur consacrent un ultime chapitre, intitulé " penser la communication ». Les théories de la communication, servies par les idéologues d'alors, nous semblent trop familières pour être tout à fait d'un autre âge. En cela, le plus grand mérite des auteurs est peut être de suggérer, de donner à penser la communication moderne sans forcer la comparaison. 